\title{
Influence of wide band gap oxide substrates on the photoelectrochemical properties and structural disorder of CdS nanoparticles grown by the successive ionic layer adsorption and reaction (SILAR) method
}

\author{
Mikalai V. Malashchonak ${ }^{1}$, Alexander V. Mazanik ${ }^{*}$, Olga V. Korolik ${ }^{2}$, \\ Eugene A. Streltsov ${ }^{1}$ and Anatoly I. Kulak ${ }^{3}$
}

\section{Full Research Paper}

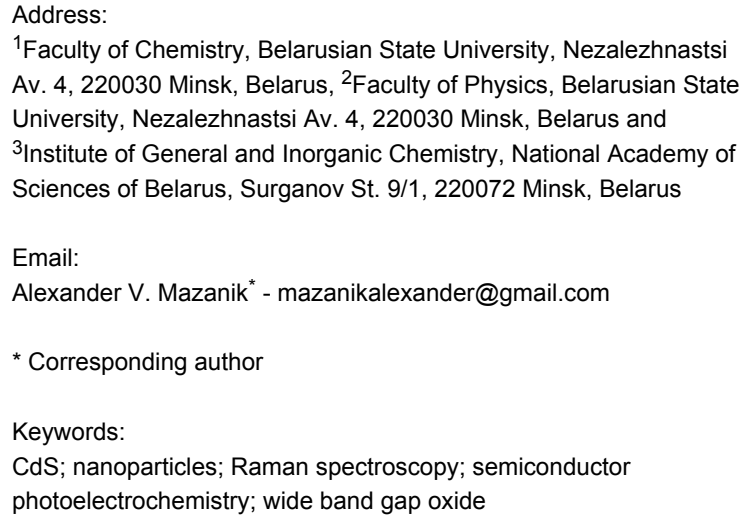

${ }^{1}$ Faculty of Chemistry, Belarusian State University, Nezalezhnastsi Av. 4, 220030 Minsk, Belarus, ${ }^{2}$ Faculty of Physics, Belarusian State University, Nezalezhnastsi Av. 4, 220030 Minsk, Belarus and 3 Institute of General and Inorganic Chemistry, National Academy of Sciences of Belarus, Surganov St. 9/1, 220072 Minsk, Belarus

Email:

Alexander V. Mazanik ${ }^{\star}$ - mazanikalexander@gmail.com

* Corresponding author

Keywords:

CdS; nanoparticles; Raman spectroscopy; semiconductor

photoelectrochemistry; wide band gap oxide

Beilstein J. Nanotechnol. 2015, 6, 2252-2262.

doi:10.3762/bjnano.6.231

Received: 12 August 2015

Accepted: 12 November 2015

Published: 30 November 2015

Associate Editor: P. Leiderer

(C) 2015 Malashchonak et al; licensee Beilstein-Institut.

License and terms: see end of document.

\footnotetext{
Abstract

The photoelectrochemical properties of nanoheterostructures based on the wide band gap oxide substrates $\left(\mathrm{ZnO}, \mathrm{TiO}_{2}, \mathrm{In}_{2} \mathrm{O}_{3}\right)$ and CdS nanoparticles deposited by the successive ionic layer adsorption and reaction (SILAR) method have been studied as a function of the CdS deposition cycle number $(N)$. The incident photon-to-current conversion efficiency (IPCE) passes through a maximum with the increase of $N$, which is ascribed to the competition between the increase in optical absorption and photocarrier recombination. The maximal IPCE values for the $\mathrm{In}_{2} \mathrm{O}_{3} / \mathrm{CdS}$ and $\mathrm{ZnO} / \mathrm{CdS}$ heterostructures are attained at $N \approx 20$, whereas for TiO $2 / \mathrm{CdS}$, the appropriate $N$ value is an order of magnitude higher. The photocurrent and Raman spectroscopy studies of CdS nanoparticles revealed the occurrence of the quantum confinement effect, demonstrating the most rapid weakening with the increase of $N$ in $\mathrm{ZnO} / \mathrm{CdS}$ heterostructures. The structural disorder of CdS nanoparticles was characterized by the Urbach energy $\left(E_{\mathrm{U}}\right)$, spectral width of the CdS longitudinal optical (LO) phonon band and the relative intensity of the surface optical (SO) phonon band in the Raman spectra. Maximal values of $E_{\mathrm{U}}(100-120 \mathrm{meV})$ correspond to CdS nanoparticles on a $\mathrm{In}_{2} \mathrm{O}_{3}$ surface, correlating with the fact that the CdS LO band spectral width and intensity ratio for the CdS SO and LO bands are maximal for $\operatorname{In}_{2} \mathrm{O}_{3} / \mathrm{CdS}$ films. A notable variation in the degree of disorder of CdS nanoparticles is observed only in the initial stages of CdS growth (several tens of deposition cycles), indicating the preservation of the nanocrystalline state of CdS over a wide range of SILAR cycles.
} 


\section{Introduction}

Quantum dot sensitized solar cells (QDSSCs) utilize light absorbed by semiconductor nanoparticles (CdS, CdSe, CdTe, $\mathrm{PbS}$, etc.) deposited on wide band gap oxide (WBGO) scaffolds $\left(\mathrm{TiO}_{2}, \mathrm{ZnO}, \mathrm{In}_{2} \mathrm{O}_{3}\right)$ which act as a photoanode [1-10]. In the last decade, the SILAR method, based on specific ionic adsorption and reaction of cations and anions [11-13], has been widely used to form chalcogenide semiconductor nanoparticles (NPs) in such structures [14,15]. This technique involves successive immersion of the electrode-substrate into solutions containing cations and anions of required elements (e.g., $\mathrm{Cd}^{2+}$ and $\mathrm{S}^{2-}$ ), thus the number of deposition cycles determines the size of the formed NPs [4,5]. Apart from its simplicity, the SILAR method provides an intimate contact of the deposit with a substrate, facilitating an efficient transfer of photogenerated carriers into an oxide matrix. Since the SILAR method allows the formation of semiconductor nanoparticles directly on a substrate, it is reasonable to expect a significant impact of the latter on the NP properties.

Despite the widespread applications of the SILAR method to form CdS NPs on an oxide substrate, its influence on the quantum efficiency of photoelectrochemical processes and the structural disorder of CdS NPs with an increasing number of SILAR cycles $(N)$ is still unclear. The aim of this study was to investigate the foregoing features to make the SILAR technique more flexible and predictable for QDSSC application.
Along with the photoelectrochemical investigation, Raman spectroscopy was used to characterize CdS NPs. Raman spectroscopy in the simplest case can be applied as a type of phase analysis $[16,17]$. At the same time, in the general case, Raman spectra are determined by both phonon and electron spectra of the system under study, electron-phonon coupling, material defectiveness, and elastic stresses, providing therefore valuable information about the NP properties. Nevertheless, to the best of our knowledge, there are no thorough studies with a systematic comparison of Raman spectra for the SILAR-grown NPs illustrating their dependence on the number of SILAR cycles and the wide band gap oxide substrate used.

\section{Results and Discussion SEM, BET, and XRD studies of $\mathrm{ZnO}, \mathrm{TiO}_{2}$, and $\ln _{2} \mathrm{O}_{3}$ electrodes}

Top and cross-sectional scanning electron microscopy (SEM) images of indium, zinc, and titanium oxide prepared films are shown in Figure 1. The $\mathrm{In}_{2} \mathrm{O}_{3}$ films (Figure 1a,d) have a uniform thickness and are characterized by a more dense packing of the grains as compared to the $\mathrm{ZnO}$ deposit, which consists of plate-like crystallites with approximately $100 \mathrm{~nm}$ thickness and a lateral size of $1-2 \mu \mathrm{m}$ (Figure $1 \mathrm{~b}, \mathrm{e}$ ). The length of the anodic $\mathrm{TiO}_{2}$ nanotubes is about $2 \mu \mathrm{m}$ (Figure 1f), and their inner diameter is several tens of nanometers (Figure 1c). The calculated Brunauer-Emmelt-Teller (BET) specific surface

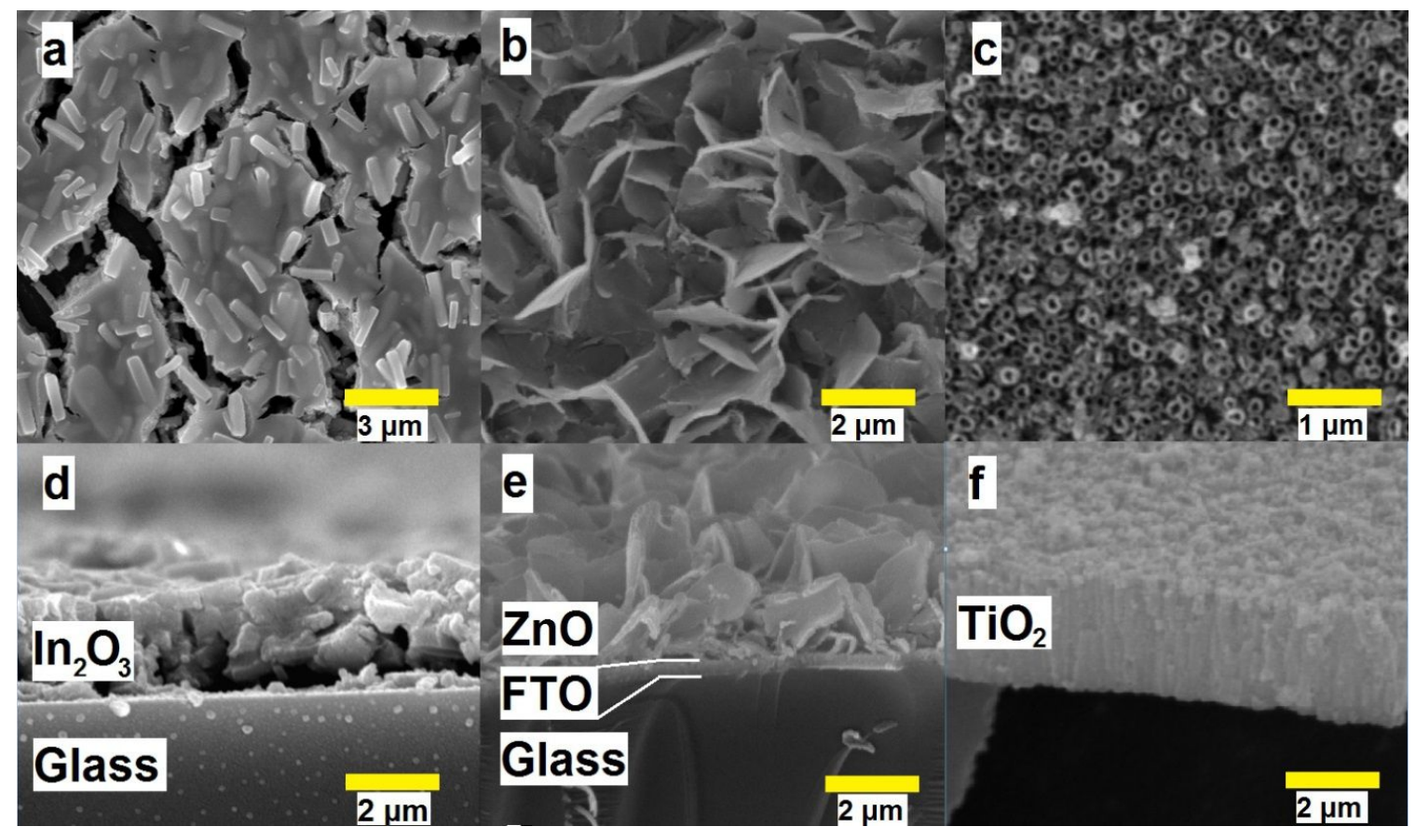

Figure 1: SEM images of $\ln _{2} \mathrm{O}_{3}$ mesoporous films (a,d), $\mathrm{ZnO}$ platelet crystallites (b,e) and anodic $\mathrm{TiO}_{2}$ nanotubes (c,f). 
area is as large as $119 \pm 8 \mathrm{~m}^{2} / \mathrm{g}$ for $\mathrm{In}_{2} \mathrm{O}_{3}$ and $105 \pm 12 \mathrm{~m}^{2} / \mathrm{g}$ for $\mathrm{ZnO}$. The specific surface area estimated from SEM images for the $\mathrm{TiO}_{2}$ nanotube array is about $20 \mathrm{~m}^{2} / \mathrm{g}$.

X-ray diffraction (XRD) analysis demonstrates that $\mathrm{In}_{2} \mathrm{O}_{3}, \mathrm{ZnO}$, and $\mathrm{TiO}_{2}$ crystallize in the cubic, hexagonal, and anatase modifications, respectively, after the heat treatment.

\section{Photoelectrochemical study of $\mathrm{ZnO} / \mathrm{CdS}$, $\mathrm{TiO}_{2} / \mathrm{CdS}$, and $\ln _{2} \mathrm{O}_{3} / \mathrm{CdS}$ heterostructures}

The incident photon-to-current conversion efficiency (IPCE) spectra of the heterostructures are presented in Figure 2. The conduction band level of CdS is located relatively higher than that of the WBGO. Therefore, the photocurrent observed for the heterostructures is attributed to the charge carrier photogeneration in CdS NPs followed by the transfer of photoelectrons into the oxide matrix, whereas the photoholes are trapped by sulphite ions, $\mathrm{SO}_{3}{ }^{2-}$. Sulfide ions $\mathrm{S}^{2-}$ in the electrolyte reduce the solubility of $\mathrm{CdS}$ and facilitate its reprecipitation during the photocorrosion process.

It should be noted that the oxide $\left(\mathrm{ZnO}, \mathrm{TiO}_{2}, \mathrm{In}_{2} \mathrm{O}_{3}\right) / \mathrm{CdS}$ heterostructures are characterized by relatively high IPCE values of up to $60-90 \%$ at a photon energy of about $3 \mathrm{eV}$. This is due to the intimate contact of SILAR-deposited CdS nanoparticles with the substrate, ensuring improved electron transfer from the NPs to the oxide matrix.
For all types of WBGO substrates the dependence of IPCE $(Y)$ on the number of SILAR cycles passes through a maximum (Figure 2d). The increase in IPCE in the range of small $N$ is naturally related to the increase in optical absorption, whereas the IPCE decrease at larger $N$ indicates the rising influence of nonequilibrium charge carrier recombination due to the increase of the distance which the photoelectrons must overcome to reach the substrate surface. The position of the maximum in the IPCE $-N$ curves is noticeably different for the different WBGOs (Figure 2d). Particularly, for $\mathrm{TiO}_{2} / \mathrm{CdS}$, the maximum is shifted towards larger $N$, and the IPCE values obtained are smaller as compared with the $\mathrm{ZnO} / \mathrm{CdS}$ and $\mathrm{In}_{2} \mathrm{O}_{3} / \mathrm{CdS}$ heterostructures. This result can be attributed to the fact that the specific area of the $\mathrm{TiO}_{2}$ nanotube array is significantly smaller in comparison with the $\mathrm{ZnO}$ and $\mathrm{In}_{2} \mathrm{O}_{3}$ films. Therefore, the light absorption in sulfide is the main factor limiting the photocurrent for the $\mathrm{TiO}_{2} / \mathrm{CdS}$ films, thus the increase in the amount of sulfide determines the IPCE growth over a wide range of $N$. At the same time, as will be shown later, the CdS NPs grown on the $\mathrm{TiO}_{2}$ surface possess a minor degree of disorder as compared with the $\mathrm{ZnO} / \mathrm{CdS}$ and $\mathrm{In}_{2} \mathrm{O}_{3} / \mathrm{CdS}$ heterostructures. Therefore, the charge carrier recombination slightly affects the photocurrent value in the $\mathrm{TiO}_{2} / \mathrm{CdS}$ system. On the contrary, in the case of the $\mathrm{In}_{2} \mathrm{O}_{3} / \mathrm{CdS}$ heterostructures, the disorder of the CdS NPs is maximal (see below), and the decrease in IPCE with increasing $N$ is observed beginning with a small number $(N \geq 20)$ of SILAR cycles. From a practical point of view, it is
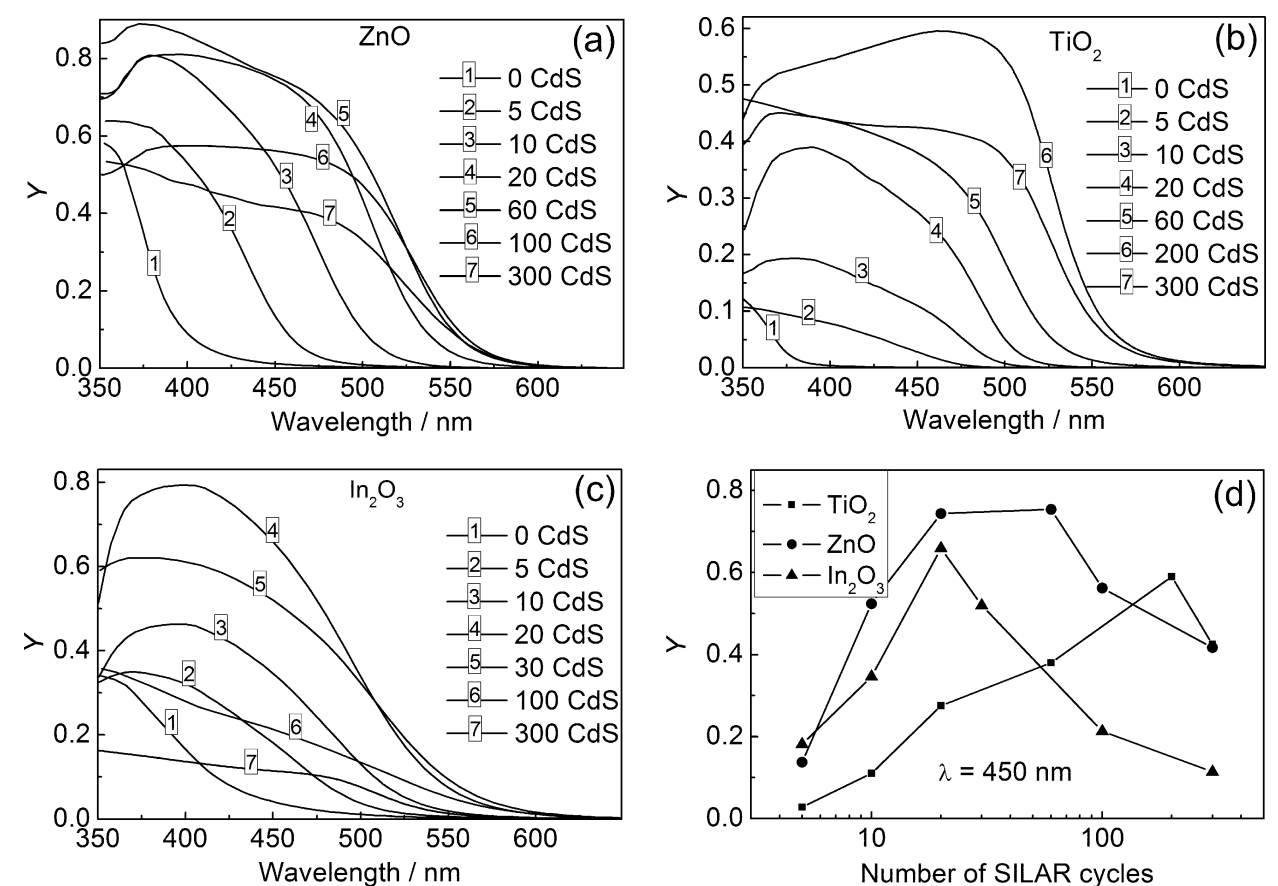

Figure 2: Spectral dependence of IPCE for $\mathrm{ZnO} / \mathrm{CdS}(\mathrm{a}), \mathrm{TiO}_{2} / \mathrm{CdS}$ (b), and $\ln _{2} \mathrm{O}_{3} / \mathrm{CdS}$ heterostructures (c). IPCE at $\lambda=450 \mathrm{~nm}$ as a function of the number of SILAR deposition cycles (d). Electrode potential: $-0.2 \mathrm{~V}$. 
important that the optimal value of the number of SILAR cycles is at least a few tens and significantly depends on the WBGO substrate used.

The amount of deposited CdS has a significant impact on the shape of the photocurrent spectra of the heterostructures. This is characterized by a red shift of the photocurrent edge with increasing $N$ (Figure $2 \mathrm{a}-\mathrm{c}$ ). The Tauc plot for direct optical transitions $(Y h v)^{2}-h v$ demonstrates that the band gap of $\mathrm{CdS}$ $\left(E_{\mathrm{g}}\right)$ significantly decreases as the number of SILAR deposition cycles increases. This holds within the range of $N=5-300$ : from 2.79 to $2.30 \mathrm{eV}$ for $\mathrm{ZnO} / \mathrm{CdS}$, from 2.77 to $2.30 \mathrm{eV}$ for $\mathrm{TiO}_{2} / \mathrm{CdS}$, and from 2.66 to $2.37 \mathrm{eV}$ for $\mathrm{In}_{2} \mathrm{O}_{3} / \mathrm{CdS}$ (Figure 3). The values of $E_{\mathrm{g}}$ evaluated from the $(Y h v)^{2}-h v$ dependence for CdS nanoparticles exceed the $E_{\mathrm{g}}$ value of $2.4 \mathrm{eV}$ for bulk cadmium sulfide at $N \leq 10$ for $\mathrm{ZnO} / \mathrm{CdS}$, at $N \leq 20$ for $\mathrm{In}_{2} \mathrm{O}_{3} / \mathrm{CdS}$, and at $N \leq 60$ for $\mathrm{TiO}_{2} / \mathrm{CdS}$, indicating an electronquantum-confinement effect. At the same time, at large $N$ the $E_{\mathrm{g}}$ values become noticeably smaller than $2.4 \mathrm{eV}$. The reasons for this effect observed for $\mathrm{ZnO} / \mathrm{CdS}$ were analyzed by Rabinovich and Hodes [15] as well as in our previous work [18]. As it is shown in [18], the sub-band gap (SBG) photoelectrochemical processes take place in $\mathrm{ZnO} / \mathrm{CdS}$ heterostructures; their IPCE can reach large values (up to $25 \%$ ) for optimized CdS NP and substrate morphology. The red shift in the photocurrent spectra with the increased number of SILAR cycles as well as the high efficiency of the SBG processes are likely to be due to light scattering from inhomogeneities in $\mathrm{ZnO} / \mathrm{CdS}$ at the comparable wavelength [18].

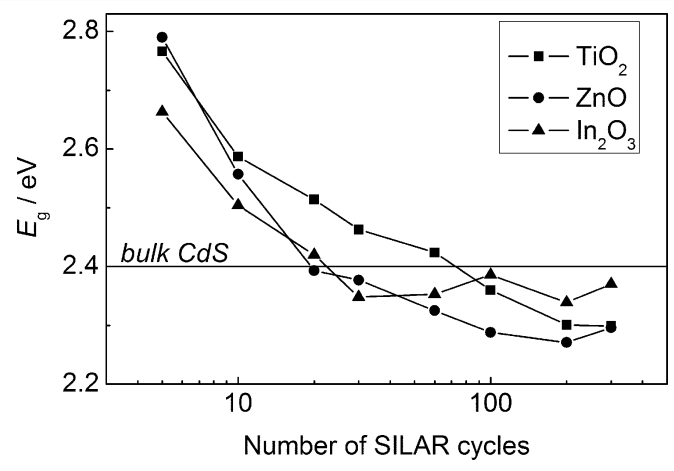

Figure 3: CdS band gap $E_{g}$ dependence on the number of SILAR deposition cycles.

There is a long-wavelength region of the photocurrent spectra for heterostructures of all three types $\left(\mathrm{ZnO} / \mathrm{CdS}, \mathrm{In}_{2} \mathrm{O}_{3} / \mathrm{CdS}\right.$, and $\mathrm{TiO}_{2} / \mathrm{CdS}$ ), where IPCE depends exponentially on the excitation energy (Figure $4 a-c$ ), i.e., the Urbach law [19] takes place.

It should be noted that the calculated Urbach energy $\left(E_{\mathrm{U}}\right)$ values given below should be considered with reasonable skepticism due to the fact that $E_{\mathrm{U}}$ is derived from the photocurrent spectrum range with a small absorption coefficient where the
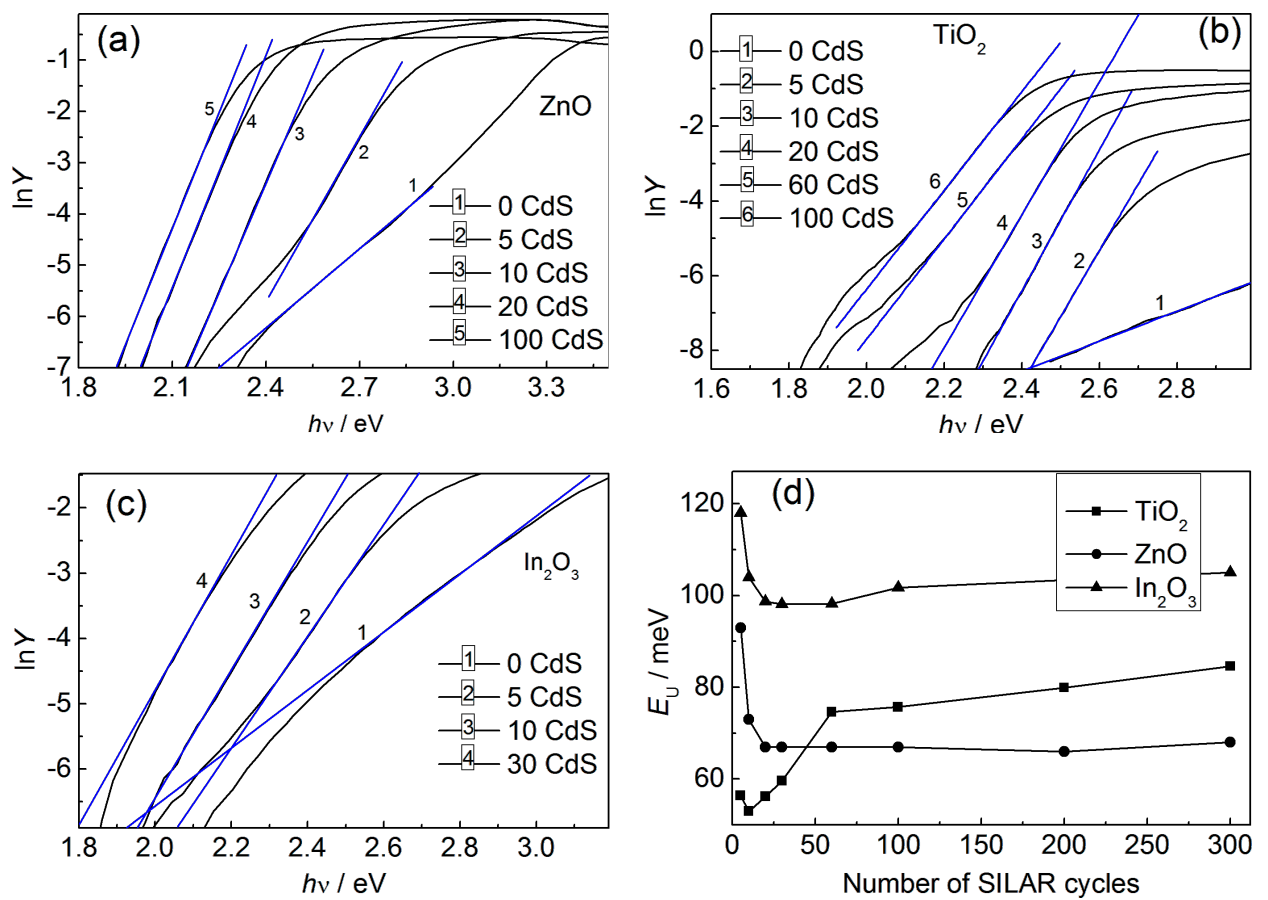

Figure 4: Spectral dependence of IPCE in $\ln Y-h v$ coordinates for $\mathrm{ZnO} / \mathrm{CdS}$ (a), $\mathrm{TiO}_{2} / \mathrm{CdS}$ (b), and $\ln _{2} \mathrm{O}_{3} / \mathrm{CdS}$ heterostructures (c). Urbach energy for CdS NPs as a function of the number of SILAR cycles (d). 
light scattering extending an optical path length is able to significantly influence the spectral dependence of the number of absorbed quanta [18]. As our additional experiments have revealed, the shape of the photocurrent spectrum in this case depends on the film morphology, which determines the efficiency of light scattering processes. As a result, the $E_{\mathrm{U}}$ value reflects not only the spectrum of electronic states, but is determined also by the microstructure of the system under study. At the same time, the Urbach energy enables one to track the variation of structural disorder with $N$, because according to the obtained SEM data, variation of the number of SILAR cycles over a wide range has no appreciable impact on the film morphology and, hence, light scattering efficiency.

The estimated Urbach energy for CdS nanoparticles as a function of $N$ is given in Figure 4d. Large $E_{\mathrm{U}}$ values (tens to
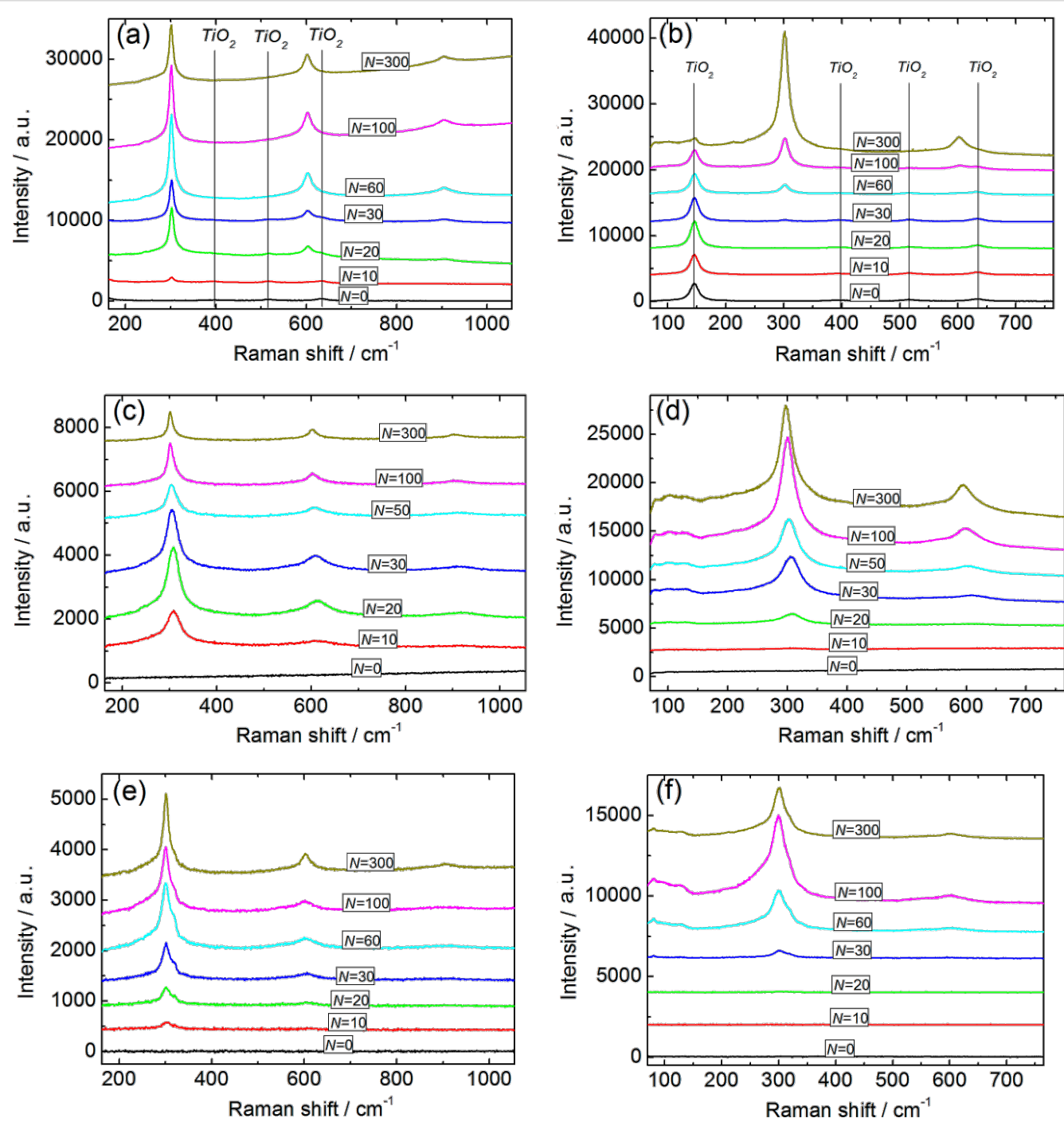

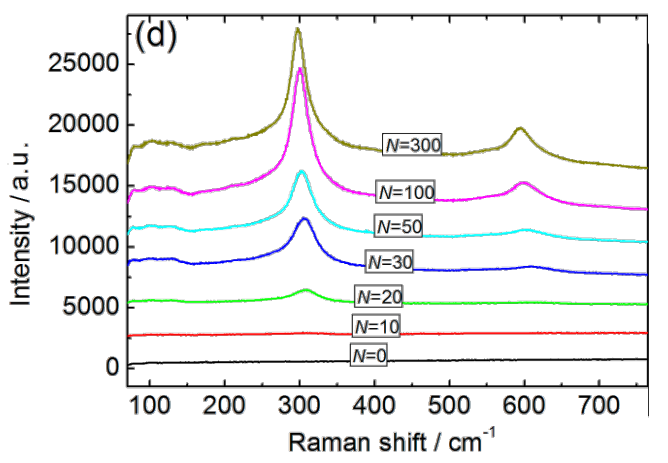

hundreds of $\mathrm{meV}$ ) indicate a high degree of structural disorder in CdS nanoparticles, which significantly depends on the oxide substrate. For $N$ ranging from 60 to $300, E_{\mathrm{U}}$ values are practically constant for $\mathrm{ZnO} / \mathrm{CdS}$ but demonstrate a slight growth for $\mathrm{In}_{2} \mathrm{O}_{3} / \mathrm{CdS}$ and $\mathrm{TiO}_{2} / \mathrm{CdS}$. This fact points out the preservation of the degree of disorder for CdS NPs over a wide range of $N$.

\section{Raman spectroscopy study of $\mathrm{ZnO} / \mathrm{CdS}$, $\mathrm{TiO}_{2} / \mathrm{CdS}$, and $\mathrm{In}_{2} \mathrm{O}_{3} / \mathrm{CdS}$ heterostructures}

The Raman spectra of $\mathrm{ZnO} / \mathrm{CdS}, \mathrm{TiO}_{2} / \mathrm{CdS}$, and $\mathrm{In}_{2} \mathrm{O}_{3} / \mathrm{CdS}$ films are shown in Figure 5. In the studied range of Raman shifts, the band at $\approx 300 \mathrm{~cm}^{-1}$ corresponded to scattering by CdS longitudinal optical (LO) phonons [20] and also two of its overtones $\left(\approx 600\right.$ and $\approx 900 \mathrm{~cm}^{-1}$ ) are observed after realization of the SILAR process, independent of the WBGO nature. Since the band gap energies for $\mathrm{In}_{2} \mathrm{O}_{3}, \mathrm{TiO}_{2}$, and $\mathrm{ZnO}$ are much

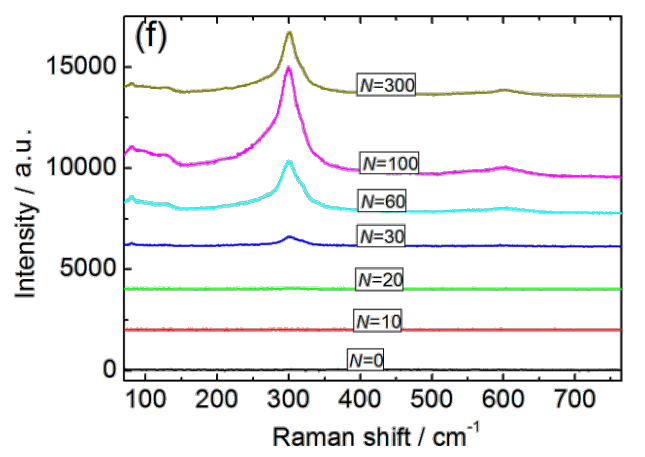


higher than the energy of the Raman spectra exciting quanta, the signals from the WBGOs have low intensities in comparison with the signal from cadmium sulfide and are almost invisible at the low excitation power used (except for $\mathrm{TiO}_{2}$, for which the Raman peak intensity is somewhat higher than that for $\mathrm{In}_{2} \mathrm{O}_{3}$ and $\mathrm{ZnO}$ ).

The approximation of the Raman spectra in the vicinity of the CdS LO band by one Lorenz line results in a significant discrepancy between the experimental and fitted contours. Along with the main band one can observe additional components in the spectral ranges corresponding to both larger and smaller Raman shifts (Figure 6).

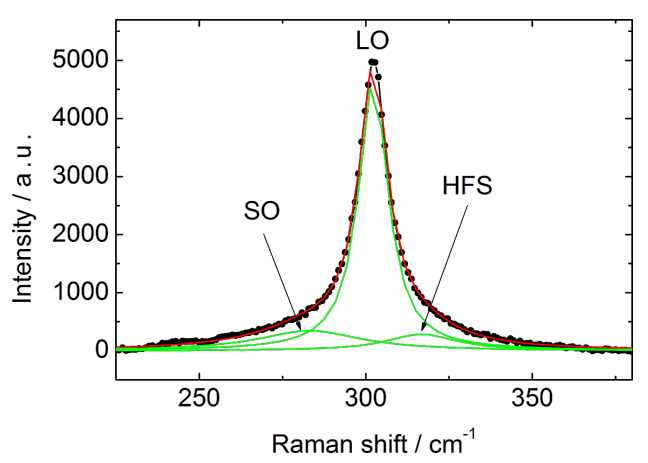

Figure 6: Approximation of Raman spectrum for $\mathrm{TiO}_{2} / \mathrm{CdS}$ film $(N=30)$ in the vicinity of the CdS LO band by superposition of the Lorentz lines.

The observed low-energy shoulder in the Raman spectra of CdS NPs in the general case may be due to the following factors: phonon confinement leading to relaxation of the $k=0$ selection rule for single-phonon scattering ( $k$ is a phonon wavevector) and an asymmetric low-energy LO band broadening [22]; scattering by disorder-activated zone-edge (DAZE) phonons [23]; or scattering by surface optical (SO) phonons [24]. As is known, the influence of phonon confinement on the line shape in Raman spectra increases with dispersion, $\omega(k)$, of optical phonons. For CdS, where the LO phonon frequency $\omega$ slightly depends on the wavevector, the impact of phonon confinement on the shape of spectral lines becomes significant only when the nanoparticles diameter is less than $2 \mathrm{~nm}$ [25]. However, in our experiments, even at $N=5$ the NP diameter, estimated from the photosensitivity edge position, exceeds $3 \mathrm{~nm}$ [26]. The band associated with scattering by DAZE phonons is observed at $\approx 293 \mathrm{~cm}^{-1}$ for CdS nanoparticles [27], that is, at much higher than the low-energy shoulder in our experiments (265-285 $\mathrm{cm}^{-1}$ depending on the WBGO). Thus, the contribution of the surface optical phonons seems to be the most likely reason for the low-energy shoulder observed in the Raman spectra.

The nature of the components in the Raman spectra in the region of the shifts exceeding the CdS LO band position is still under discussion. As the early pioneering work revealed [20], the bands at $328 \mathrm{~cm}^{-1}$ and $347 \mathrm{~cm}^{-1}$ correspond to two-phonon scattering in CdS. Nevertheless, it behooves us to consider that in our case these components are not only associated with the two-phonon processes, in particular because the relative probability of two-phonon scattering in nanoparticles is smaller than in the bulk material. In a prior work [28], the signal in this spectral region (according to this work it will be denoted as a highfrequency shoulder (HFS)) was tentatively related to the undercoordinated atoms on the surface of the nanoparticle.

The dependence of the CdS LO band intensity on the number of SILAR cycles demonstrates a sharp increase in the signal at small $N$ followed by a slight decrease (Figure 7). In the case of $532 \mathrm{~nm}$ excitation, a sharp increase in the signal intensity is observed at larger $N$ values. This result is in agreement with the above-mentioned $E_{\mathrm{g}}(N)$ dependence. Indeed, the intensity of the Raman signal reaches its maximum when the energy of exciting photons equals the band gap of the semiconductor [29]. For small $N$ values, due to the quantum-confinement effect, the
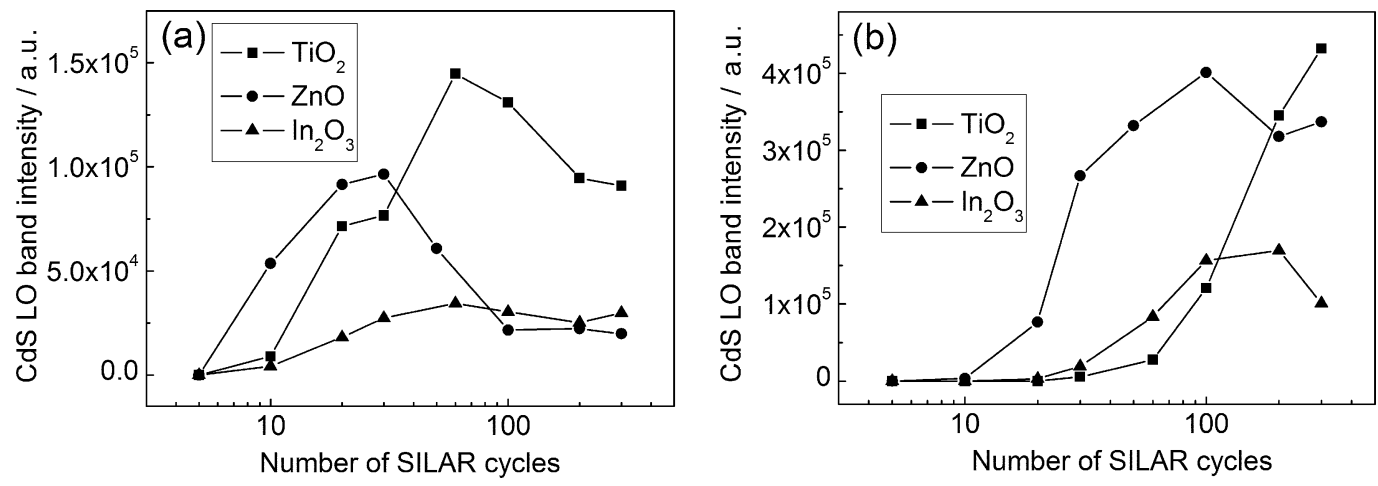

Figure 7: Intensity of CdS LO band as a function of the SILAR cycle number. Excitation: $473 \mathrm{~nm} / 25 \mu \mathrm{W}$ (a) and $532 \mathrm{~nm} / 200 \mu \mathrm{W}$ (b). 
band gap energy of CdS NPs exceeds the energy of the exciting radiation quanta, $h v$. Thus the increase in $N$ leads not only to an increase in the amount of $\mathrm{CdS}$ in the films, but also to the increased probability of Raman scattering. This is because the band gap energy of the NPs is reduced to $h v$ due to weakening of the quantum-confinement effect. For this reason, at an early stage in the SILAR process, the signal intensity grows faster than the CdS amount. Due to the further weakening of the quantum-confinement effect in CdS nanoparticles, at larger $N$, the photon energy exceeds $E_{\mathrm{g}}$ and the signal intensity decreases. When a green laser is used for excitation, $E_{\mathrm{g}}$ reaches $h v$ at a larger $N$ (as compared to the case of $473 \mathrm{~nm}$ excitation), which is in agreement with the experimental results.

A rapid increase in the $\mathrm{CdS} \mathrm{LO}$ band intensity for $\mathrm{ZnO} / \mathrm{CdS}$ structures starts at smaller $N$ values in comparison with $\mathrm{In}_{2} \mathrm{O}_{3} / \mathrm{CdS}$ and $\mathrm{TiO}_{2} / \mathrm{CdS}$ films (Figure 7). This fact coincides with the $E_{\mathrm{g}}(N)$ dependence (Figure 3), which demonstrate that the most rapid weakening of the electron-quantum-confinement effect with increasing $N$ is observed for the $\mathrm{ZnO} / \mathrm{CdS}$ structures. Thus in the range $5 \leq N \leq 20$ the $\mathrm{d} E_{\mathrm{g}} / \mathrm{d} N$ absolute values are equal to $26 \mathrm{meV} /$ cycle for $\mathrm{ZnO} / \mathrm{CdS}$ and $16-17 \mathrm{meV} /$ cycle for $\mathrm{In}_{2} \mathrm{O}_{3} / \mathrm{CdS}$ and $\mathrm{TiO}_{2} / \mathrm{CdS}$.

The observed difference in the $\mathrm{d} E_{\mathrm{g}} / \mathrm{d} N$ values points to a more rapid growth of CdS NPs on the $\mathrm{ZnO}$ surface. As the first step of SILAR process in our experiments is an adsorption of $\mathrm{Cd}^{2+}$ cations on the surface of WBGO, the dependence of the CdS NP growth rate on the WBGO material may be related to the difference in the $\mathrm{Cd}^{2+}$ adsorption efficiency. The adsorption of $\mathrm{Cd}^{2+}$ on the surface of $\mathrm{ZnO}$ nanoparticles is extremely efficient and the maximum adsorption capacity was estimated to be $387 \mathrm{mg} / \mathrm{g}$ [30]. At the same time, the adsorption capacity of the $\mathrm{TiO}_{2}$ surface is considerably lower and ranges within 4-60 mg/g, depending on the nanoparticle size (decreases with increasing size) [31]. It is reasonable to assume that the high surface concentration of $\mathrm{Cd}^{2+}$, as well as the identity of CdS and $\mathrm{ZnO}$ lattices, promotes a more rapid growth of the $\mathrm{CdS}$ nuclei on the $\mathrm{ZnO}$ surface at an early stage in the SILAR process. There is no published data on the adsorption of $\mathrm{Cd}^{2+}$ on the surface of $\operatorname{In}_{2} \mathrm{O}_{3}$, but we can assume that it is significantly smaller in comparison with the surface of $\mathrm{ZnO}$. It is common knowledge that the process of cation adsorption on an oxide surface is largely determined by the equilibrium of protolytic reactions (surface concentration of acid-base centers) and temperature $[31,32]$. In particular, the increase in $\mathrm{OH}^{-}$ surface concentration enhances the adsorption of $\mathrm{Cd}^{2+}$ due to the formation of barely soluble cadmium hydroxide. $\mathrm{ZnO}$ and $\mathrm{In}_{2} \mathrm{O}_{3}$ can give a sub-monolayer of $\mathrm{Zn}(\mathrm{OH})_{2}$ and $\mathrm{In}(\mathrm{OH})_{3}$, respectively, upon contact with water. The solubility products of these compounds are $2.3 \cdot 10^{-17}$ and $1.3 \cdot 10^{-37}$, respectively [33]. Thus the estimated value of the $\mathrm{OH}^{-}$surface concentration derived from these constants is four orders of magnitude higher in the case of $\mathrm{Zn}(\mathrm{OH})_{2}$ as compared with $\operatorname{In}(\mathrm{OH})_{3}$.

The $\mathrm{In}_{2} \mathrm{O}_{3} / \mathrm{CdS}$ and $\mathrm{TiO}_{2} / \mathrm{CdS}$ films were characterized by very close CdS LO band positions that are practically independent of both the deposition cycle number and the energy of exciting quanta (Figure 8). At the same time, for $\mathrm{ZnO} / \mathrm{CdS}$ films, the $\mathrm{LO}$ band position is shifted by several reciprocal centimeters to the region of larger Raman shifts; at small $N$ it exceeds the LO band position of bulk CdS (302-305 $\mathrm{cm}^{-1}$, as reported by numerous authors) and monotonically shifts towards lower values with increasing $N$. We attribute this result to the compressive lattice stresses in CdS nanoparticles (due to a mismatch of the CdS and $\mathrm{ZnO}$ lattice parameters) and to the relaxation of these stresses with increasing nanoparticle size in $\mathrm{ZnO} / \mathrm{CdS}$ films [18].

Figure 9 presents the CdS LO band full width at half maximum (FWHM) as a function of the deposition cycle number. It is worth noting that $\mathrm{ZnO} / \mathrm{CdS}$ films are characterized by a considerably broader (by 10-20 $\mathrm{cm}^{-1}$ ) spectral width of the LO band
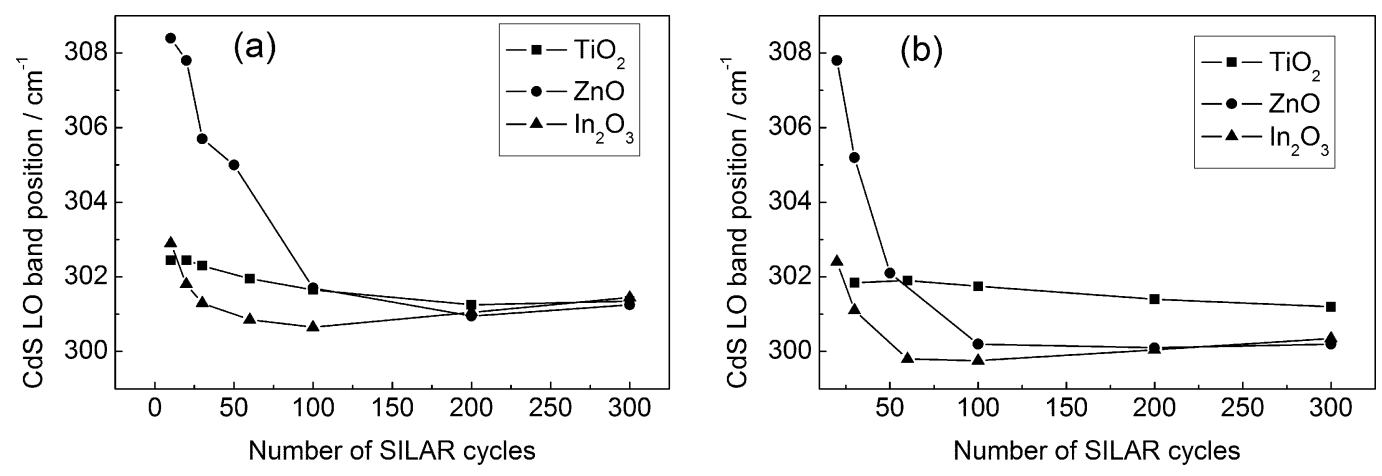

Figure 8: Position of CdS LO band as a function of the SILAR cycle number. Excitation: $473 \mathrm{~nm} / 25 \mu \mathrm{W}$ (a) and $532 \mathrm{~nm} / 200 \mu \mathrm{W}$ (b). 

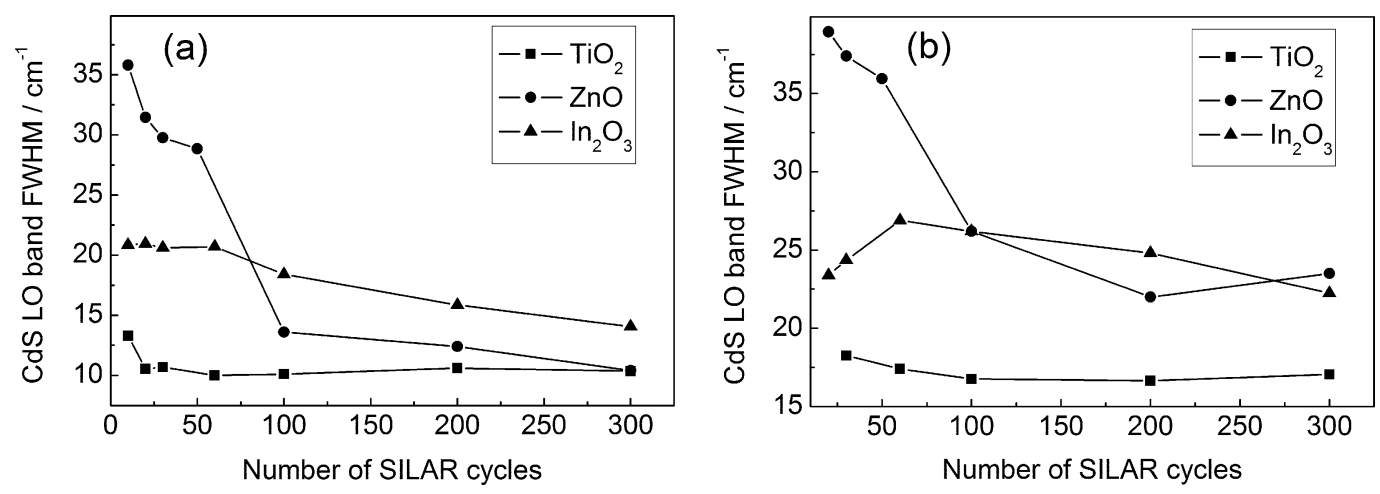

Figure 9: FWHM of CdS LO band as a function of the SILAR cycle number. Excitation: $473 \mathrm{~nm} / 25 \mu \mathrm{W}$ (a) and $532 \mathrm{~nm} / 200 \mu \mathrm{W}$ (b).

for $N<100$. This fact is in agreement with the presence of elastic deformations in the cadmium sulfide nanoparticles synthesized on the surface of $\mathrm{ZnO}$. Indeed, the spectral width of the Raman line increases with the decreasing phonon mean-free path determined by the scattering processes from defects as well as by the decay (conversion to another two phonons) [34]. A contribution of the latter to the Raman line broadening increases with the anharmonicity of atomic oscillations. The anharmonicity contribution is more substantial in the deformed lattice. This results in the experimentally observed large spectral width of the CdS LO band for $\mathrm{CdS} / \mathrm{ZnO}$ films at $N<100$ and its decrease with a growth of $N$ due to the stress relaxation.

The CdS LO band width for $\operatorname{In}_{2} \mathrm{O}_{3} / \mathrm{CdS}$ films is larger than for $\mathrm{TiO}_{2} / \mathrm{CdS}$, which corresponds with the results of the photoelectrochemical measurements demonstrating a larger Urbach energy for the nanoparticles synthesized on the surface of indium oxide.

The spectral widths of the CdS LO band for all films studied are $5-10 \mathrm{~cm}^{-1}$ wider when excited by a green laser. This fact can be explained by the Urbach energy dispersion in the ensemble of CdS nanoparticles [35]. Under excitation with a blue laser, the condition $h v_{\mathrm{bl}}>E_{g}$ holds, which results in resonant scattering for the entire ensemble of nanoparticles. At the same time, when using a green laser, the condition $h v_{\mathrm{gr}}<E_{g}$ is realized, thus resonant scattering is possible only for the most disordered CdS particles characterized by the highest Urbach energy. The dispersion of the Urbach energies of CdS nanoparticles is in agreement with the decrease in the relative intensity of the CdS $I_{2 \mathrm{LO}}$ band (scattering by two LO phonons) when changing from blue to green excitation light (Figure 10).

The intensity ratio of the bands associated with $\mathrm{CdS}$ SO and CdS LO phonons is given in Figure 11. The maximal $I_{\mathrm{SO}} / I_{\mathrm{LO}}$ ratio is peculiar for the $\mathrm{In}_{2} \mathrm{O}_{3} / \mathrm{CdS}$ films and correlates with the maximal values of the CdS LO band spectral width and the Urbach energy for the CdS NPs formed on $\operatorname{In}_{2} \mathrm{O}_{3}$. A weak dependence of the $I_{\mathrm{SO}} / I_{\mathrm{LO}}$ ratio on the CdS deposition cycle number might seem unexpected. Meanwhile, this result correlates well with a weak dependence of the CdS LO band width and $E_{\mathrm{U}}$ on the deposition cycle number. This was also
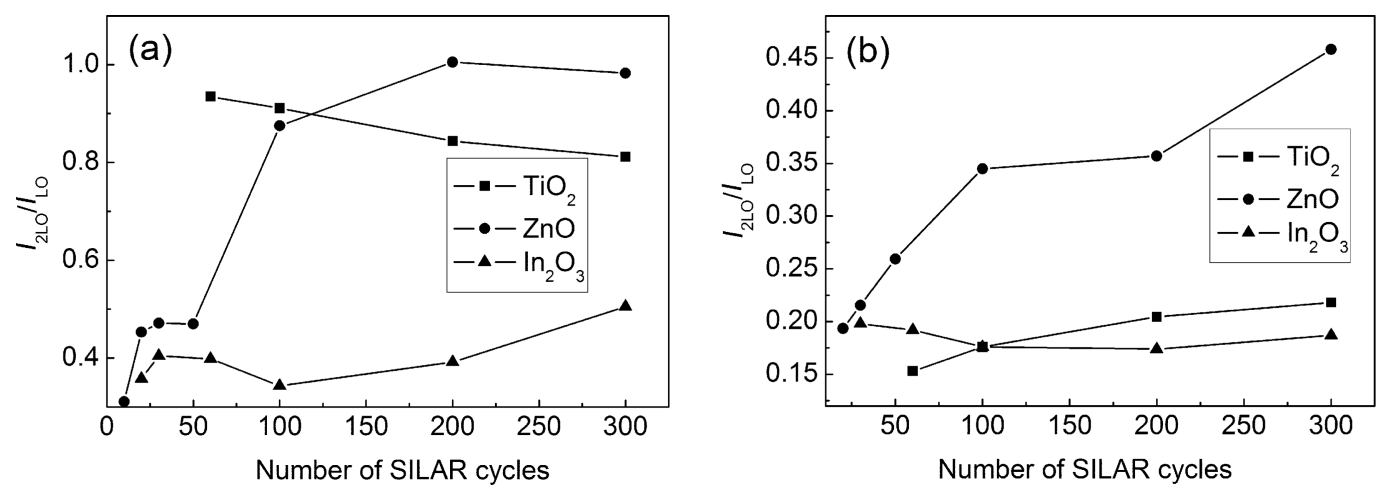

Figure 10: Intensity ratio of CdS $2 \mathrm{LO}$ and LO bands as a function of the SILAR cycle number. Excitation: $473 \mathrm{~nm} / 25 \mu \mathrm{W}$ (a) and $532 \mathrm{~nm} / 200 \mu \mathrm{W}$ (b). 

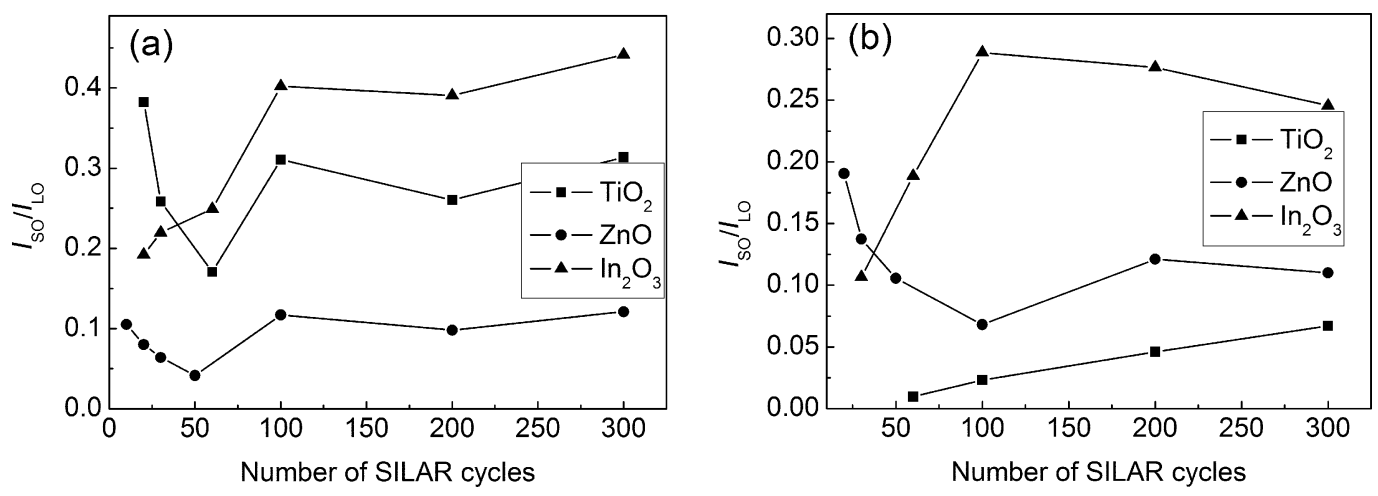

Figure 11: Intensity ratio of CdS SO and LO bands as a function of the SILAR cycle number. Excitation: $473 \mathrm{~nm} / 25 \mu \mathrm{W}$ (a) and $532 \mathrm{~nm} / 200 \mu \mathrm{W}$ (b).

confirmed by X-ray data which show that even at $N=300$, the size of the coherent scattering regions in CdS NPs estimated by Scherrer's equation is below $10 \mathrm{~nm}$.

\section{Conclusion}

Similarities and distinctions in the photoelectrochemical behavior of the systems based on WBGOs $\left(\mathrm{ZnO}, \mathrm{TiO}_{2}, \mathrm{In}_{2} \mathrm{O}_{3}\right)$ sensitized by the SILAR-grown CdS nanoparticles have been established. Regardless of the WBGO material, at a small number of SILAR deposition cycles, the electron-quantum-confinement effect determines the spectral range of the photoelectrochemical activity. The most rapid weakening of the quantumconfinement effect with increasing $N$ is observed in the $\mathrm{ZnO} / \mathrm{CdS}$ structures, probably due to enhanced $\mathrm{Cd}^{2+}$ ion adsorption on the $\mathrm{ZnO}$ surface. CdS NPs grown on the WBGO surface possess a high degree of structural disorder, which was characterized by the Urbach energy, spectral width of the CdS LO band and relative intensity of CdS SO and LO bands from the Raman spectra. A higher degree of the structural disorder is peculiar for the CdS NPs crystallized on the $\operatorname{In}_{2} \mathrm{O}_{3}$ surface. Significant changes in the Urbach energy are observed only during the early stage of CdS deposition $(N<20-60)$. The preservation of the degree of disorder of the CdS NPs at a large number of SILAR cycles indicates that their nanocrystalline state is maintained. For all types of systems studied, the dependence of IPCE on the number of SILAR cycles, $N$, is non-monotonic and influenced by the competition of two processes: the increase in the optical absorption with $N$ (i.e., with the amount of $\mathrm{CdS}$ ) and the simultaneous enhancement of the recombination role due to the increased distance the photogenerated charge carriers must overcome. The number of $N$ corresponding to the maximal IPCE values should be at least several tens and depends essentially on the substrate used due to the above-mentioned revealed distinctions in properties of nanoheterostructures based on the different WBGOs.

\section{Experimental}

$\mathrm{ZnO}, \mathrm{In}_{2} \mathrm{O}_{3}$ and $\mathrm{TiO}_{2}$ films were synthesized on FTO, ITO and titanium, respectively.

Mesoporous $\mathrm{In}_{2} \mathrm{O}_{3}$ films were prepared by spin coating of an indium hydroxide colloidal solution with subsequent heat treatment [36]. A stable indium hydroxide sol was prepared by hydrolysis of a $0.25 \mathrm{~mol} / \mathrm{L} \mathrm{In}\left(\mathrm{NO}_{3}\right)_{3}$ solution with aqueous ammonia (12\%) under vigorous stirring at $0{ }^{\circ} \mathrm{C}$ to attain $\mathrm{pH} 8$. The indium hydroxide precipitate was carefully washed with distilled water and sonicated after adding of $1.5 \mathrm{~mL}$ of concentrated nitric acid $(65 \%)$ as a stabilizer per $50 \mathrm{~mL}$ of sol. The obtained $\mathrm{In}(\mathrm{OH})_{3}$ sol with a concentration of $200 \mathrm{~g} / \mathrm{L}$ was mixed with a Pluronic F127 block copolymer (with average molecular mass of $12500 \mathrm{~g} / \mathrm{mol}$ ) in a ratio of $5 \mathrm{~g}$ of polymer per $50 \mathrm{~mL}$ of sol. ITO substrates were degreased and thoroughly washed in the boiling mixture of $\mathrm{H}_{2} \mathrm{O}_{2}$ and $\mathrm{NH}_{3}$ followed by spin coating with the obtained $\operatorname{In}(\mathrm{OH})_{3} \mathrm{sol}$ at $3000 \mathrm{rpm}$ for $30 \mathrm{~s}$ and heat treatment for $1 \mathrm{~h}$ at $400{ }^{\circ} \mathrm{C}$ in air.

The synthesis of the titanium dioxide nanotube arrays was carried out in a two-electrode electrochemical cell by anodization of metallic titanium with a graphite counter electrode in an aqueous electrolyte containing $1 \mathrm{~mol} / \mathrm{L}\left(\mathrm{NH}_{4}\right)_{2} \mathrm{SO}_{4}$, $0.1 \mathrm{~mol} / \mathrm{L} \mathrm{NH}_{4} \mathrm{~F}$ and $0.2 \mathrm{~mol} / \mathrm{L} \mathrm{H}_{2} \mathrm{C}_{2} \mathrm{O}_{4}$ with $\mathrm{pH} 2.8$ (corrected with $\mathrm{NaOH}$ ) under the electrode potential bias of $25 \mathrm{~V}$ for $20 \mathrm{~h}$ at room temperature [37]. The rate of potential bias sweep from 0 to $25 \mathrm{~V}$ at the initial stage was $250 \mathrm{mV} / \mathrm{s}$. After anodization, the electrodes were immediately immersed into a $1.2 \mathrm{~mol} / \mathrm{L}$ $\left(\mathrm{NH}_{4}\right)_{2} \mathrm{SO}_{4}$ solution for $24 \mathrm{~h}$ then rinsed with distilled water, air-dried and heat-treated at $450{ }^{\circ} \mathrm{C}$ for $1 \mathrm{~h}$ in air.

Mesoporous zinc oxide films were prepared by the electrochemical cathodic deposition from water-ethanol (1:1 by volume) electrolyte containing $0.1 \mathrm{~mol} / \mathrm{L} \mathrm{Zn}\left(\mathrm{NO}_{3}\right)_{2}, 0.1 \mathrm{~mol} / \mathrm{L} \mathrm{KCl}$ and 
$4 \mathrm{~g} / \mathrm{L}$ poly(vinylpyrrolidone) at $50{ }^{\circ} \mathrm{C}[18,38]$. Deposition was carried out by potentiostatic cathodic polarization of FTO electrodes at $-1000 \mathrm{mV}$ vs $\mathrm{Ag} / \mathrm{AgCl} / \mathrm{KCl}$ (sat.) reference electrode $(+0.201 \mathrm{~V}$ vs SHE) for $25 \mathrm{~min}$. Because of the formation of hydroxyl ions, a local increase of $\mathrm{pH}$ occurs, and the hydrolysis of $\mathrm{Zn}^{2+}$ ions is promoted and precipitation of $\mathrm{Zn}_{5}(\mathrm{OH})_{8} \mathrm{Cl}_{2}$ on the electrode surface occurs. This is confirmed by the X-ray diffraction analysis $[18,38]$. The heating of the obtained films in air at $360{ }^{\circ} \mathrm{C}$ results in decomposition of zinc hydroxychloride with the formation of zinc oxide.

The chemical deposition of CdS on the surface of oxide ( $\mathrm{ZnO}$, $\mathrm{TiO}_{2}, \mathrm{In}_{2} \mathrm{O}_{3}$ ) films was carried out by successive adsorption of cadmium and sulfide ions by means of alternating immersion of the substrates into $0.1 \mathrm{~mol} / \mathrm{L} \mathrm{Cd}\left(\mathrm{NO}_{3}\right)_{2}$ and $0.01 \mathrm{~mol} / \mathrm{L} \mathrm{Na}_{2} \mathrm{~S}$ aqueous solutions under vigorous stirring accompanied by intermediate rinsing with distilled water after each immersion. The duration of sample exposure in each solution and rinsing was $1 \mathrm{~min}$. The cycle was repeated 5-300 times, then the sample was washed with distilled water and dried in air.

SEM images were obtained with a LEO 1455 VP scanning electron microscope. The BET surface area and porosity measurements were performed using an ASAP2020MP analyzer (Micromeritics, USA). Adsorption isotherms were obtained with $\mathrm{N}_{2}$ at $77 \mathrm{~K}$. The surface area was calculated from the linear part of the BET plot. X-ray diffraction analysis was carried out on a Bruker D8 Advance diffractometer using $\mathrm{Cu} \mathrm{K} \alpha$ radiation in the Bragg-Brentano geometry.

The photoelectrochemical measurements were performed according to the procedure described in [39]. A standard twocompartment three-electrode cell containing a platinum counter electrode and an $\mathrm{Ag} / \mathrm{AgCl} / \mathrm{KCl}$ (sat.) electrode as the reference electrode and controlled by a conventional programmable potentiostat was used. The photocurrent spectra were obtained using a setup equipped with a high-intensity grating monochromator (spectral resolution $1 \mathrm{~nm}$ ), a $250 \mathrm{~W}$ halogen lamp, and an optical chopper. The spectral dependence of the incident photon-to-current conversion efficiency was calculated from the photocurrent spectra with a correction for the light intensity distribution at the monochromator output. The photoelectrochemical measurements were carried out in $1 \mathrm{~mol} / \mathrm{L} \mathrm{Na}_{2} \mathrm{SO}_{3}+$ $0.1 \mathrm{~mol} / \mathrm{L} \mathrm{NaOH}+0.01 \mathrm{~mol} / \mathrm{L} \mathrm{Na}_{2} \mathrm{~S}$ aqueous solution.

The Raman spectra were recorded at room temperature using a Nanofinder HE (LOTIS TII, Belarus-Japan) confocal spectrometer. Two solid-state lasers emitting at $473 \mathrm{~nm}\left(h v_{\mathrm{bl}}=2.62 \mathrm{eV}\right)$ and $532 \mathrm{~nm}\left(h v_{\mathrm{gr}}=2.33 \mathrm{eV}\right)$ were used for excitation of the samples. The backscattered light was dispersed on a 1800 lines/mm diffraction grating with a spectral resolution better than $1 \mathrm{~cm}^{-1}$ and detected using a thermostated CCD matrix with a signal acquisition time typically equal to $120 \mathrm{~s}$. Calibration was performed by means of a built-in gas discharge lamp to an accuracy of $\approx 1 \mathrm{~cm}^{-1}$.

\section{Acknowledgements}

The work was financially supported by the Research Program "Electronics and Photonics" of the Republic of Belarus (contract No. 2.2.19).

\section{References}

1. Rühle, S.; Shalom, M.; Zaban, A. ChemPhysChem 2010, 11, 2290-2304. doi:10.1002/cphc.201000069

2. Jun, H. K.; Careem, M. A.; Arof, A. K. Renewable Sustainable Energy Rev. 2013, 22, 148-167. doi:10.1016/j.rser.2013.01.030

3. Kamat, P. V. J. Phys. Chem. C 2008, 112, 18737-18753. doi:10.1021/jp806791s

4. Baker, D. R.; Kamat, P. V. Adv. Funct. Mater. 2009, 19, 805-811. doi:10.1002/adfm.200801173

5. Kamat, P. V.; Tvrdy, K.; Baker, D. R.; Radich, J. G. Chem. Rev. 2010, 110, 6664-6688. doi:10.1021/cr100243p

6. Hetsch, F.; Xu, X.; Wang, H.; Kershaw, S. V.; Rogach, A. L. J. Phys. Chem. Lett. 2011, 2, 1879-1887. doi:10.1021/jz200802j

7. Nozik, A. J.; Beard, M. C.; Luther, J. M.; Law, M.; Ellingson, R. J.; Johnson, J. C. Chem. Rev. 2010, 110, 6873-6890. doi:10.1021/cr900289f

8. Kamat, P. V. J. Phys. Chem. Lett. 2013, 4, 908-918. doi:10.1021/jz400052e

9. Kouhnavard, M.; Ikeda, S.; Ludin, N. A.; Ahmad Khairudin, N. B.; Ghaffari, B. V.; Mat-Teridi, M. A.; Ibrahim, M. A.; Sepeai, S.; Sopian, K. Renewable Sustainable Energy Rev. 2014, 37, 397-407. doi:10.1016/j.rser.2014.05.023

10. Duan, J.; Zhang, H.; Tang, Q.; He, B.; Yu, L. J. Mater. Chem. A 2015, 3, 17497-17510. doi:10.1039/C5TA03280F

11. Nicolau, Y. F. Appl. Surf. Sci. 1985, 22-23, 1061-1074. doi:10.1016/0378-5963(85)90241-7

12. Nicolau, Y. F.; Dupuy, M.; Brunel, M. J. Electrochem. Soc. 1990, 137, 2915-2924. doi:10.1149/1.2087099

13. Pathan, H. M.; Lokhande, C. D. Bull. Mater. Sci. 2004, 27, 85-111. doi:10.1007/BF02708491

14. Cheng, S.; Fu, W.; Yang, H.; Zhang, L.; Ma, J.; Zhao, H.; Sun, M.; Yang, L. J. Phys. Chem. C 2012, 116, 2615-2621. doi:10.1021/jp209258r

15. Rabinovich, E.; Hodes, G. J. Phys. Chem. C 2013, 117, 1611-1620. doi:10.1021/jp3105453

16. Mali, S. S.; Devan, R. S.; Ma, Y.-R.; Betty, C. A.; Bhosale, P. N.; Panmand, R. P.; Kale, B. B.; Jadkar, S. R.; Patil, P. S.; Kim, J.-H.; Chang, K. H. Electrochim. Acta 2013, 90, 666-672. doi:10.1016/j.electacta.2012.12.017

17. Wu, G.; Shen, Y.; Wu, Q.; Gu, F.; Cao, M.; Wang, L. J. Alloys Compd. 2013, 551, 176-179. doi:10.1016/j.jallcom.2012.10.017

18. Malashchonak, M. V.; Streltsov, E. A.; Mazanik, A. V.; Kulak, A. I.; Poznyak, S. K.; Stroyuk, O. L.; Kuchmiy, S. Ya.; Gaiduk, P. I. Thin Solid Films 2015, 589, 145-152. doi:10.1016/j.tsf.2015.04.057 19. Urbach, F. Phys. Rev. 1953, 92, 1324. doi:10.1103/PhysRev.92.1324 20. Tell, B.; Damen, T. C.; Porto, S. P. S. Phys. Rev. 1966, 144, 771-774. doi:10.1103/PhysRev.144.771 
21. Sekiya, T.; Ohta, S.; Kamei, S.; Hanakawa, M.; Kurita, S. J. Phys. Chem. Solids 2001, 62, 717-721. doi:10.1016/S0022-3697(00)00229-8

22. Richter, H.; Wang, Z. P.; Ley, L. Solid State Commun. 1981, 39 , 625-629. doi:10.1016/0038-1098(81)90337-9

23. Barker, A. S., Jr.; Sievers, A. J. Rev. Mod. Phys. 1975, 47, S1-S179. doi:10.1103/RevModPhys.47.S1.2

24. Roy, A.; Sood, A. K. Phys. Rev. B 1996, 53, 12127-12132. doi:10.1103/PhysRevB.53.12127

25. Dzhagan, V.; Mel'nik, N.; Rayevska, O.; Grozdyuk, G.; Strelchuk, V.; Plyashechnik, O.; Kuchmii, S.; Valakh, M. Phys. Status Solidi RRL 2011, 5, 250-252. doi:10.1002/pssr.201105219

26. Kozytskiy, A. V.; Stroyuk, O. L.; Kuchmiy, S. Ya.; Mazanik, A. V.; Poznyak, S. K.; Streltsov, E. A.; Kulak, A. I.; Korolik, O. V.; Dzhagan, V. M. Thin Solid Films 2014, 562, 56-62. doi:10.1016/j.tsf.2014.03.070

27. Ingale, A.; Rustagi, K. C. Phys. Rev. B 1998, 58, 7197-7204 doi:10.1103/PhysRevB.58.7197

28. Dzhagan, V. M.; Valakh, M. Ya.; Himcinschi, C.; Milekhin, A. G.; Solonenko, D.; Yeryukov, N. A.; Raevskaya, O. E.; Stroyuk, O. L.; Zahn, D. R. T. J. Phys. Chem. C 2014, 118, 19492-19497. doi:10.1021/jp506307q

29. Yu, P. Y.; Cardona, M. Fundamentals of Semiconductors; Springer: Berlin, Germany, 2005.

30. Sheela, T.; Arthoba Nayaka, Y.; Viswanatha, R.; Basavanna, S.; Venkatesha, T. G. Powder Technol. 2012, 217, 163-170. doi:10.1016/j.powtec.2011.10.023

31. Gao, Y.; Wahi, R.; Kan, A. T.; Falkner, J. C.; Colvin, V. L.; Tomson, M. B. Langmuir 2004, 20, 9585-9593. doi:10.1021/la049334i

32. Janusz, W.; Matysek, M. J. Colloid Interface Sci. 2006, 296, 22-29. doi:10.1016/j.jcis.2005.08.067

33. Lidin, R. A.; Andreeva, L. P.; Molochko, V. A. Spravochnik po Neorganicheskoi Khimii. Konstanty Neorganicheskikh Veshchestv (The Handbook in Inorganic Chemistry. The Constants of Inorganic Substances); Khimiya: Moscow, Russia, 1987.

34. Falkovsky, L. A. Phys.-Usp. 2004, 47, 249-272. doi:10.1070/PU2004v047n03ABEH001735

35. Dzhagan, V.; Rayevskaya, O.; Stroyuk, O.; Kuchmiy, S.; Zahn, D. R. T. Phys. Status Solidi C 2009, 6, 2043-2046. doi:10.1002/pssc.200881755

36. Poznyak, S. K.; Kulak, A. I. Electrochim. Acta 2000, 45, 1595-1605. doi:10.1016/S0013-4686(99)00319-9

37. Cai, Q.; Paulose, M.; Varghese, O. K.; Grimes, C. A. J. Mater. Res. 2005, 20, 230-236. doi:10.1557/JMR.2005.0020

38. Kozytskiy, A. V.; Stroyuk, A. L.; Kuchmy, S. Ya.; Skorik, N. A.; Moskalyuk, V. O. Theor. Exp. Chem. 2012, 48, 331-337. doi:10.1007/s11237-012-9278-2

39. Poznyak, S. K.; Golubev, A. N.; Kulak, A. I. Surf. Sci. 2000, 454-456, 396-401. doi:10.1016/S0039-6028(00)00064-9

\section{License and Terms}

This is an Open Access article under the terms of the Creative Commons Attribution License

(http://creativecommons.org/licenses/by/2.0), which permits unrestricted use, distribution, and reproduction in any medium, provided the original work is properly cited.

The license is subject to the Beilstein Journal of Nanotechnology terms and conditions:

(http://www.beilstein-journals.org/bjnano)

The definitive version of this article is the electronic one which can be found at:

doi:10.3762/bjnano.6.231 